\title{
Business Incubation Performance in the Malaysian ICT Sector
}

\author{
Fararishah Binti Abdul Khalid
}

Juhaini Jabar

\author{
Aminuddin Ahmad Kayani
}

\author{
David Gilbert
}

\begin{abstract}
This paper presents research on ICT incubation performance in Malaysia detailing contrasting outcomes predicated upon a number of factors modelled in this study including 'Selection Performance', 'Monitoring and Business Assistance Intensity', 'Resource Allocation', and 'Professional Management Services'. It also aims at addressing the lack of knowledge concerning the underlying components impacting on ICT incubation performance in Malaysia. Building on the theoretical work of researchers in the field such as Hackett \& Dilts $(2004 ; 2008)$ who analysed the literature in chronological order identifying five primary research orientations in incubation (incubator development; incubator configurations; incubatee development; incubator-incubation impacts; and theorising about business incubation); four research propositions were developed for this study. A total of 180 participants were asked to respond to a questionnaire and 118 useable responses were received yielding a response rate of $65.6 \%$. The research results highlight that a 'one-size-fits-all' approach is inappropriate. Whilst the four propositions developed for this research were all confirmed, it is telling that highly performed incubator firms were very much in the minority. Interestingly, resources provided became less significant as incubatees became more profitable whilst targeted professional management services increased in significance suggesting that as profitability improves the need for capability development increases.
\end{abstract}

Keywords: incubation, performance, incubatee development, ICT sector, business incubators Subject classification codes: include these here if the journal requires them

\section{INTRODUCTION}

The advent of business incubators in the late 1950s is attributed by the National Business Incubation Association (NBIA) in the U.S. to Frank Mancuso the then mayor of Batavia, a small city located in the western region of the state of New York. The city, in the 1950s faced problems not too dissimilar to issues facing many towns, regions and nations in current times including structural transitions due to the erosion of manufacturing opportunities and capability as well as job losses and stagnation in economic growth and development. In particular, detrimental impacts were being felt at the SME level and it was obvious to Mancuso that if actions were not taken, the backbone of his community would surely suffer further atrophy. His solution was for he and his brothers to convert a vacant chicken incubator into a gathering place for would be entrepreneurs with basic shared services and peppercorn rental rates. The notion of business incubators as an economic development tool was born and the number of incubator programs in the U.S. has grown from 12 in the 1980s to around 1,400 by the end of 2012, creating approximately 49,000 sustainable companies, more than 245,000 jobs and $\$ 15$ billion in annual revenue (NBIA, 2012). The concept of a collective aimed at fostering access to resources, capability enhancement, networking, collaboration and 
knowledge spill-overs whilst reducing costs to fragile new businesses and off-setting risk to such start-ups and incubator sponsors has now been embraced worldwide. Indeed, various forms of incubators are readily witnessed in many countries from more basic enterprise centres to sophisticated technology and science parks. The utility of business incubation as an economic development tool has not gone unnoticed in the developing world with many countries like Malaysia articulating and developing strategies around incubation in an effort to fast track their progress towards developed nation status. Moreover, in this digital age of business encompassing global markets and practices, information and communication technology (ICT) incubation in particular is heralded as critical to a nation's innovation capability commanding significant investment in infrastructure, management expertise and policy development.

This paper presents research on ICT incubation performance in Malaysia detailing contrasting outcomes predicated upon a number of factors modelled in this study including 'Selection Performance', 'Monitoring and Business Assistance Intensity', 'Resource Allocation', and 'Professional Management Services'. Surprisingly, even though there exists general acknowledgement that business incubation can be effective in accelerating growth, researchers in the field such as Peters, Rice, and Sundararajan (2004), Bruneel, Ratinho, Clarysse, Groen, and Cock (2010) and Hackett and Dilts (2008) note that despite concerted calls for further research there remains a lack of clarity concerning the relationships between elements of the incubation process and incubation performance. Furthermore, in developing countries such as Malaysia where more comprehensive understanding of business incubation has the potential to advance the transition from labour-intensive economies to knowledge-based economies, empirical research is in even greater need. In answering this need, this paper proceeds as follows: firstly, business incubation in Malaysia is examined with particular emphasis on ICT incubation. Secondly, research propositions and the conceptual model developed in guiding data collection and analyses are presented. Thirdly, results from the exploratory factor analysis and subsequent multinomial logistic regression are detailed. Finally, implications of the findings are discussed with recommendations for practice offered as well as directions for future research.

\section{ICT BUSINESS INCUBATION IN THE MALAYSIAN CONTEXT}

Small to Medium Enterprises (SMEs) constitute $99.2 \%$ of total business establishments in Malaysia, some 518,996 SMEs in total (Che Senik, 2010). Of the total number of SMEs, 86.5\% are in the services sector. Whilst the ICT sector is viewed as a critical growth industry in Malaysia and has been strongly supported by the government (Ghazi, 2006), the number of accredited ICT companies totals just 2,645 (MdeC, 2015). This represents only $0.42 \%$ of the total SMEs in the services sector raising concerns regarding ICT SME development efforts. Growth of the SME sector and in particular ICT SMEs is identified as one of the government's top priorities in the 'Third Outline Perspective Plan' (OPP3) developed to promote the longterm economic prosperity of the country (Ramasamy, B., Chakrabarty, A. \& Cheah, 2003).

Integral to this strategic plan is MSC Malaysia (formerly known as Multimedia Super Corridor launched in 1996), a project developed primarily to spearhead the growth of the ICT industry in the country and to provide a test-bed for the global ICT industry. The MSC covers an area of more than 750 square kilometres extending south from Malaysia's capital city and business hub, Kuala Lumpur. MSC Malaysia offers state-of-the-art ICT and multimedia facilities and infrastructure in 'Cybercities' (e.g Cyberjaya) required by companies to potentially elevate the local ICT sector into a world class industry (Hassan \& Omar 2010). The MSC project receives substantial financial support from the government, e.g. in the $8^{\text {th }}$ Malaysia Plan, MSC projects were allocated the highest development allocation of RM1.8 billion (approximately US\$556 
million). Moreover, ICT continues to be promoted as one of the National Key Economic Areas (NKEAs) in the 10 $10^{\text {th }}$ Malaysia Plan; a five-year plan for 2011 to 2015 that aims to move Malaysia to high-income status by 2020 (Ramasamy, 2011). The Government of Malaysia has stressed the importance of business incubation as a key initiative in projected economic development, and through Public-Private Partnerships (PPP) for example, it has co-invested with the private sector in ICT development through government funding agencies such as the Malaysian Venture Capital Management Berhad (MAVCAP), the Malaysian Technology Development Corporation (MTDC), and Ekuiti Nasional Berhad (EKUINAS).

Despite this concerted support of the ICT sector as a catalyst to achieve Malaysia's 2020 vision of becoming a developed country, limited empirical research on incubation in Malaysia has been undertaken. Information regarding business incubation has been primarily descriptive, originating from consultants' survey reports and government white papers; and provides a rather limited understanding of current practices and performance (Mohd Saffar, 2007). This view is also supported by the Tenth Malaysia Plan which details that the impact, effectiveness, and sustainability of incubators has been inconsistent (Malaysian Plan, 2010).

\section{Evolution of business incubators in Malaysia}

ICT business incubators in Malaysia have evolved through a number of generations, each exhibiting gradual improvement in terms of the availability of services and resources. Figure 1 presents the classification of incubators from first-generation to third-generation incubators in Malaysia. Grimaldi and Grandi (2005) observed that the existence of different incubators and the evolution of business incubator models over time were necessary to accommodate the requirements and needs of businesses, which in turn drives diversity in service provision at incubators.

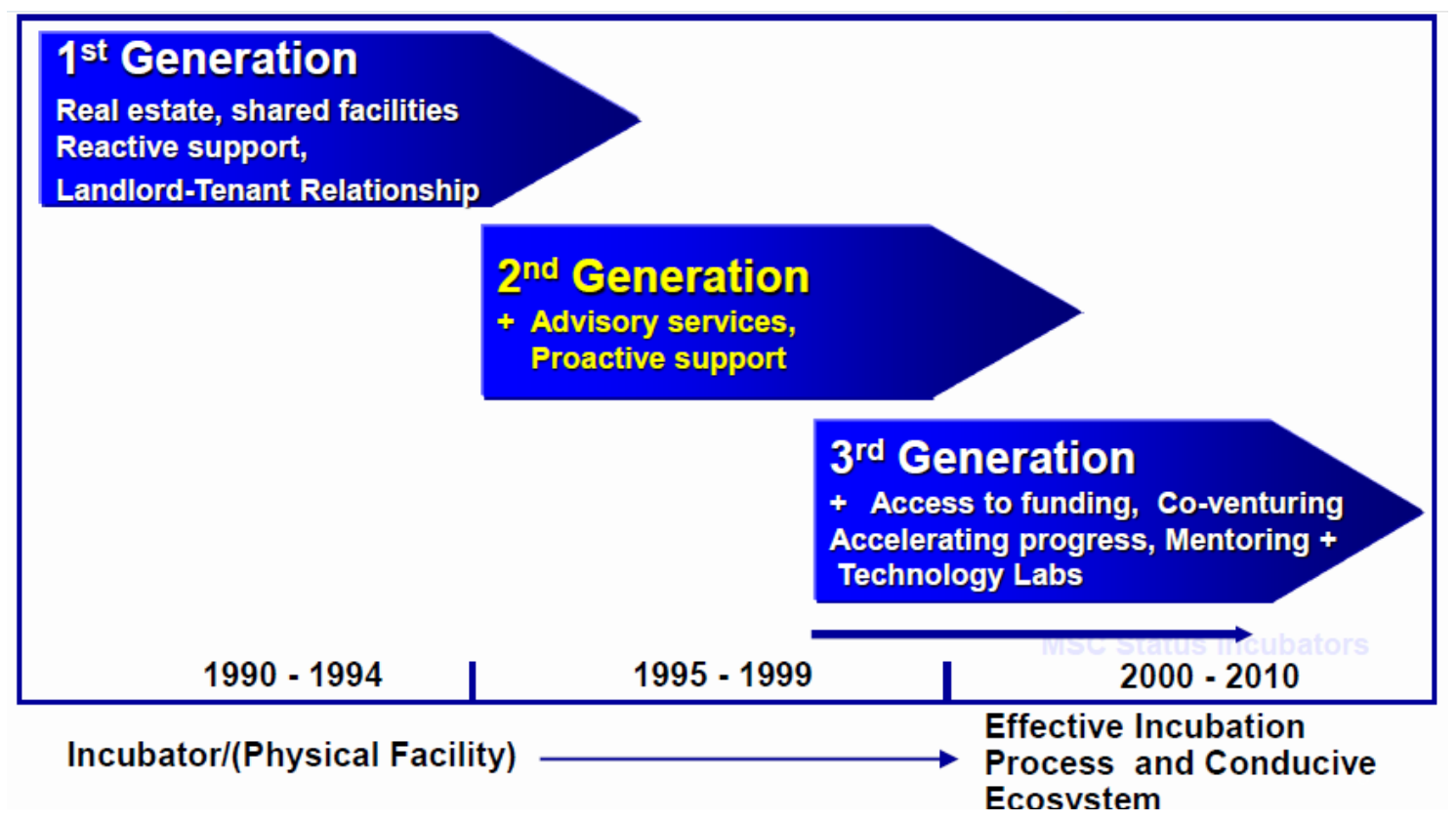

Figure 1: Evolution of business incubators in Malaysia (Mohd Saffar, 2007)

According to Mohd Saffar (2007) most incubators in developing countries are still trapped in the first and second-generation types of incubators, characterised by a landlord-tenant relationship where shared facilities are offered at nominal rents with variable support offered, usually on an ad-hoc basis. This situation, according to the National Incubator Network Association (NINA) in Malaysia, is reflected by the development trajectory in Malaysian ICT incubators. With a total population of 106 incubators, $77.3 \%$ of the incubators are classified to 
be in the first two generations, that is 38 incubators deemed to be first-generation and 44 second-generation incubators with the remaining 24 from the population classified as thirdgeneration incubators (Mohd Saffar, 2007). The number of incubators in the third-generation model that offers more sophisticated facilities such as technology labs is comparatively low, indicating there is a pressing need to investigate the constituent elements of the incubation process and their impacts on incubation performance. However, according to Abdul Khalid, Gilbert, and Huq (2012), third-generation incubators are still far from realization. It is a major concern that the majority of the literature to date has focused more upon the outcomes of the business-incubation process such as program sustainability and growth, incubatees' survival and growth, contributions to the sponsoring university's mission, and community-related impacts (Mian, 1994), rather than the processes that created such outputs (Albert \& Bernasconi, 2002; Bergek \& Norrman, 2008; McAdam \& McAdam, 2008; Sun \& Leung, 2007)

There is a view expressed in the literature that much of the work to date is largely anecdotal in nature and the concept of how business incubators create, develop and sustain SMEs remains fairly rudimentary. According to Hackett and Dilts (2008) in Warren, Patton, and Bream (2009, pg. 485) Warren et al. (2009, p. 485), there has been little effort beyond the work of Campbell, Kendrick and Samuelson (1985) to "unpack the variables associated with the incubation process". Given this perceived dearth of knowledge and research surrounding the underlying elements and effectiveness of the incubation process combined with an almost absence of work in the Malaysian context, particularly in the ICT industry, this research empirically examines the business incubation process and impacts associated with incubation performance.

Problems identified with Malaysian incubators are often associated with the management of the incubators. Many incubator managers are deemed not to have adequate entrepreneurial skills to run the incubators (Jusoh, 2006; Mohd Saffar, 2007). These managers are schooled to perform rational management paradigm i.e. planning/organising/leading/controlling, while business start-ups especially incubatees require a little more entrepreneurial guidance. Likewise, these incubator managers have been observed to lack the capabilities and experience critical for new businesses to survive and prosper. As a result, many incubatees fail to meet their goal of launching a successful business. This has driven the government to re-examine the viability of the incubator programs, aiming to improve the situation. The incubators still have a strong tendency to mirror the landlord-tenant model and despite the government's initiatives to transform the incubator status to third-generation models, evidence suggests that "incubators in Malaysia are not properly managed, leading to the discouraging number of startups going out of business" (Jusoh, 2006, p. 28).

The reality is there appears to be a lack of management capability in incubators in Malaysia. Compounding this, widespread evidence of duplication in tasks in developing technopreneurs in Malaysia has been observed, leading to a "lack of coordination, implementation procedures and wastage of resources" (Mohd Saffar, 2007, p. 8). The various tasks are taken up by a number of agencies that report to different Ministries, causing an undesirable duplication of roles and responsibilities (Robinson, 2010). For example, technology incubators, general incubators, and agro incubators are placed under the Ministry of Science, Technology, and Innovation, the Ministry of Entrepreneurship Cooperation and Development, and the Ministry of Agriculture and Agro-based Industries respectively. Because of this, incubators in some states may not have the same privileged facilities as other incubators do in the Kuala Lumpur area, which is regarded as a more positive locale for the incubation industry. Given such obstacles constraining the success of Malaysian incubators to date and that extant literature with reference to the Malaysian incubation landscape reflects the underdeveloped status of the 
subject (Mohd Yunos, 2001), this current research is timely. Information regarding the status of Malaysian incubators and the incubation system can be found in professional literature appearing on websites, annual incubator reports, consultancy surveys, benchmarking reports, magazines, and in various other publications (Infodev, 2008), however, there is a concerning lack of empirically-based research. To date, there has been no comprehensive study that specifically aims to investigate the ICT incubation process and its influence on business incubation performance. Researchers such as Ghazi (2006) and Jusoh (2006) lament that limited existing research in the Malaysian context merely report the 'status of the incubation system', focusing on non-specific types of incubators and offering little insight into experience. In response, this study addresses this lack of knowledge concerning the underlying components impacting on ICT incubation performance in Malaysia. Building on the theoretical work of researchers in the field such as Hackett (2004) and Hackett and Dilts (2008) who analysed the literature in chronological order identifying five primary research orientations in incubation (incubator development; incubator configurations; incubatee development; incubator-incubation impacts; and theorising about business incubation); four research propositions were developed for this study. These are discussed in the following section accompanied by presentation of the conceptual model that guided data collection and analysis.

\section{Conceptual model and research propositions}

\section{METHOD}

The conceptual model tested in this study was developed following an extensive literature review that examined in particular empirical studies on business incubation. These studies were predominantly undertaken in developed countries Hackett and Dilts (2004) or Hamdani (2006) with a fewer number of studies carried out in developing countries Chan and Lau (2005) or Bulsara, Porey, and Gandhi (2010). From this review, four multi-dimensional constructs emerged comprising of factors found to impact on the success (or not) of business incubation in the various countries and industries that the research was conducted in. Subsequently, a pilot study was conducted involving managers of ICT incubators to test the appropriateness of these constructs and factors germane to the Malaysian context that resulted in six case studies being developed (which will be reported on in a forthcoming article). The constructs used to examine business incubation performance in Malaysian ICT incubators are: 'Selection Performance', 'Monitoring and Business Assistance Intensity', 'Resource Allocation', and 'Professional Management Services'. Figure 2 presents the conceptual model underpinning this study. 


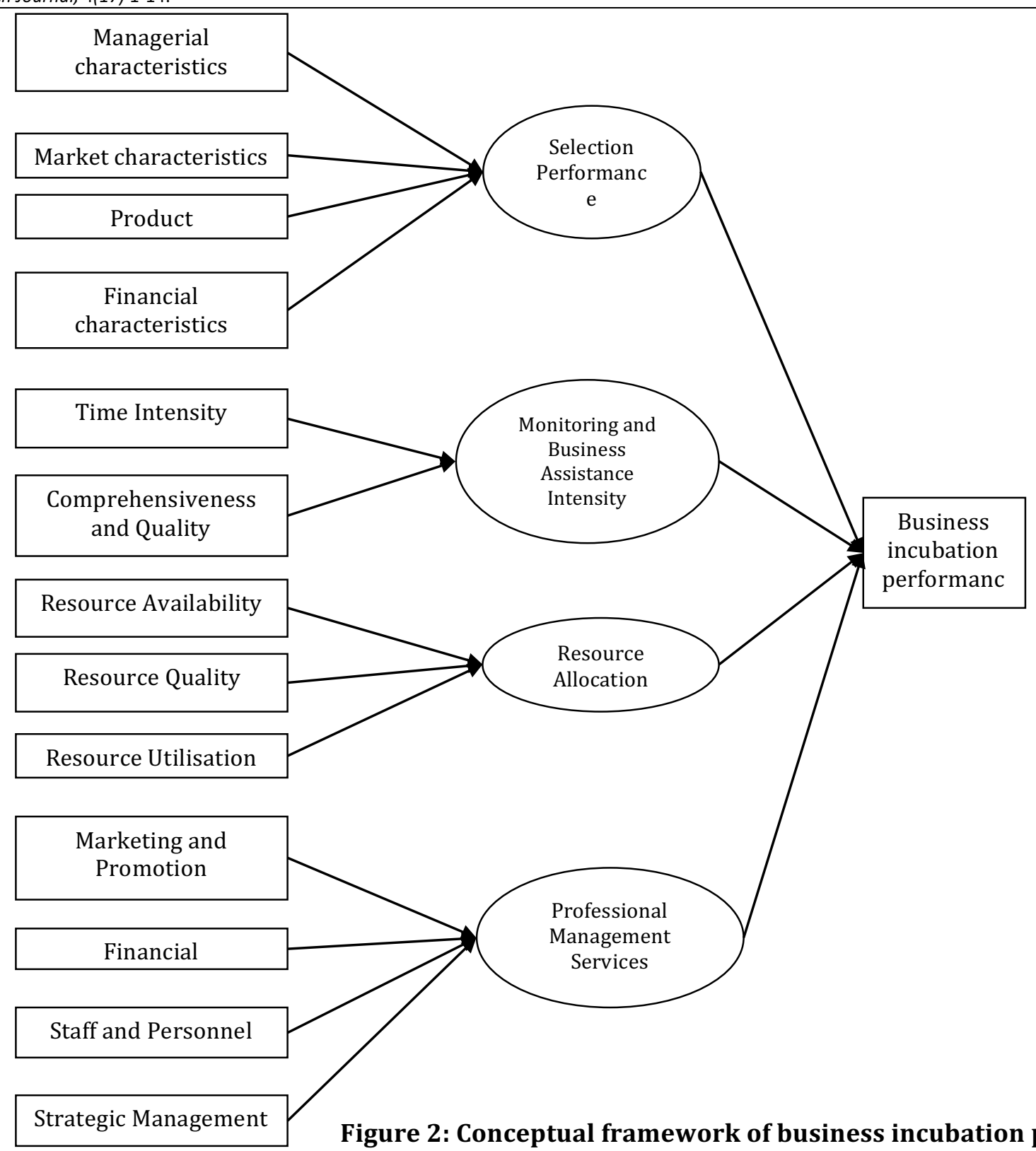

Figure 2: Conceptual framework of business incubation process

Four propositions were tested in this study as follows:

Proposition 1: A systematic approach to selection performance will more likely result in better incubation performance

Proposition 2: Incubatees are more likely to perform when monitoring and business assistance are provided

Proposition 3: Incubatees are more likely to perform when appropriate incubator resources are allocated

Proposition 4: Incubatees are more likely to perform when targeted Professional Management Services are provided

\section{Sample and data collection}

A total number of 180 ICT incubatee businesses were identified by the National Incubator Network Association (NINA). A letter inviting each to participate in the research and a link to an on-line survey were emailed to all 180 potential participants. In total, 118 useable responses were received yielding a response rate of $65.6 \%$. The survey instrument comprised of 251 items organised into six sections covering descriptive details of respondents, multiple item measures relating to the four independent variables ('Selection Performance', 'Monitoring 
and Business Assistance Intensity', 'Resource Allocation', and 'Professional Management Services') and four categorical outcomes for business incubation performance developed from the work of Hackett and Dilts (2004; 2008) that included: (1) 'Our company is barely surviving'; (2) 'Our company has met its break-even and is moving on a path towards profitability'; (3) 'Our company is making profit', and (4) 'Our company is highly profitable'.

\section{Data Analysis}

Data analyses were undertaken in three principal stages (data screening, exploratory factor analysis (EFA), and multinomial logistic regression) using SPSS Statistics 18.0. Data were tested for violations of statistical assumptions including multicollinearity, outliers, and normality, as well as identification of missing data. Subsequently, Principle Component Analysis (PCA) with Varimax rotation was undertaken to determine the number of components associated with Selection Performance, Monitoring and Business Assistance Intensity, Resource Allocation, Professional Management Services, and Business Incubation Performance. Due to the categorical nature of the dependent variable (Business Incubation Performance), multinomial logistic regression was then used to model the magnitude of effects of the four independent variables on Business Incubation Performance. After transforming the dependent variable into a logit variable to gain the natural log of the odds of the dependent state occurring or not, maximum likelihood estimation was applied to realise the probability of the four business incubation performance outcomes occurring. To interpret the analysis, log-likelihood ratios were calculated to evaluate changes in the log odds of the independent variables in assessing the fit of the model by using observed and predicted values. Pearson Chi-square and Deviance Statistics were calculated to measure goodness-of-fit via observed and expected frequencies and measures of association. Odds Ratios were also generated to examine the change in odds of outcomes occurring resulting from a single unit change in the predictors.

\section{EFA}

\section{RESULTS}

The data set was assessed for normality, homogeneity of variance, and scedasticity and subsequently common methods variance using Harman's one-factor test. As well, standardised means for each variable were examined to exclude outliers followed by tests for skewness and kurtosis and Kaiser's measure of sampling adequacy. The data set was deemed suitable for factor analysis and PCA performed resulting in eleven components loading on the four constructs. The eleven components were comprised of 86 measurement items and accounted for $79.2 \%$ of the variance explained. Factor loadings ranged from .534 to .898 and the internal consistency of the items measuring the latent constructs all showed a high degree of reliability as detailed in Table 1. 
Table 1. PCA results

\begin{tabular}{|l|c|l|c|}
\hline \multirow{2}{*}{ Construct } & Component & Component Label & $\begin{array}{c}\text { Cronbach's } \\
\text { Alpha }\end{array}$ \\
\hline \multirow{3}{*}{ Selection Performance } & 1 & Market and managerial based selection & .921 \\
\cline { 2 - 4 } & 2 & Product-based selection & .926 \\
\cline { 2 - 4 } & 3 & Financial-based selection & .880 \\
\hline Monitoring and Business & 4 & Comprehensiveness and Quality & .967 \\
\cline { 2 - 4 } Assistance Intensity & 5 & Time Intensity & .854 \\
\hline \multirow{2}{*}{ Resource Allocation } & 6 & Resource Utilisation and Quality & .958 \\
\cline { 2 - 4 } & 7 & Resource Availability & .958 \\
\hline \multirow{3}{*}{$\begin{array}{l}\text { Professional Management } \\
\text { Services }\end{array}$} & 8 & Staff and Personnel Management & .964 \\
\cline { 2 - 4 } & 9 & Financial Management & .945 \\
\cline { 2 - 4 } & 10 & Marketing and Promotion Management & .942 \\
\cline { 2 - 4 } & 11 & Strategic Management & .955 \\
\hline
\end{tabular}

\section{Regression model(s)}

The eleven extracted components comprised of 86 measurement items from the PCA were used as predictor variables for the multinomial logistic regression to test the four research propositions and model the relationships with the four categorical outcomes of business incubation performance. Peng, Lee and Ingersoll's (2002) approach to logistic regression evaluation was followed based on: (1) overall model evaluation, (2) statistical tests of individual predictors, (3) goodness-of-fit statistics, and (4) validation of predicted probabilities. The prediction probabilities were used to examine the goodness-of-fit of the regression to the model with the regression scores calculating the likelihood of each component extracted from the factor analysis predicting incubation performance. Forward conditional stepwise logistic regression analysis was performed in five phases consisting of a full model analysis followed by four individual model analyses. The full model analysis incorporated the entire eleven components from the factor analysis grouped under their respective parent constructs to test any relationships with the four categorical outcomes. The full model results are presented in this paper and highlight the significance of the four constructs in predicting incubation performance.

\section{Overall model evaluation}

The logistic model provides a better fit to the data if it demonstrates an improvement over the intercept-only model or null model which provides a baseline, as it contains no predictors. Table 2 presents the overall model evaluation consisting of all four constructs. Results indicate that the probability of the model chi-square (14.02) was .003, which is less than the level of significance of .05 and that Selection Performance (F1), Monitoring and Business Assistance Intensity (F2), Resource Allocation (F3), and Professional Management Services (F4) are all significant in predicting business incubation performance $(p<.05)$.

Table 2. Full logistic regression model fit results

\begin{tabular}{|c|c|c|c|}
\hline Predictors & Chi-Square & df & $\mathbf{P}$ \\
\hline Intercept & 18.43 & 3 & .001 \\
\hline Selection Performance (F1) & 13.02 & 3 & .005 \\
\hline Monitoring and Business Assistance Intensity (F2) & 9.50 & 3 & .023 \\
\hline Resource Allocation (F3) & 8.75 & 3 & .031 \\
\hline Professional Management Services (F4) & 13.39 & 3 & .004 \\
\hline Final & 14.02 & 3 & .003 \\
\hline
\end{tabular}

As detailed, the dependent variable in the model, 'Business Incubation Performance' is measured by four categorical outcomes. The first outcome ('Our company is barely surviving') 
was used as a reference category. Hence, three outcome categories have been specified from the data: Category 1 - Our company has met its break even and is moving toward profitability; Category 2 - Our company is making profit; and Category 3 - Our company is highly profitable'. Table 3 presents the parameter estimates for the full model including the log odds value used to predict business incubation performance from the four independent variables. Results indicate Category 1 shows no significant relationship between the constructs and business incubation performance with all values of $p$ greater than the significance level of .05. However, Categories 2 and 3 show significant relationships with business incubation performance, with Selection Performance $(p=.009)$ for Category 2 and $(p=.048)$ for Category 3; Monitoring and Business Assistance Intensity $(p=.016)$ for Category 2, and Professional Management Services $(p=.010)$ for Category 2 , and $(p=.041)$ for Category 3 . Examining the log odds of the three categories we are able to gauge the impact of a one-unit change in the independent variables on the log odds of the dependent variable. For example in Category 2, a positive relationship between the dependent variable 'Our company is making profit' and the independent variable 'Selection Performance' is observed whereby the likelihood of a company making profit through better Selection Performance is increased by a factor of 1.215 (or 21.5\%). Similarly, with $p=.016$, a unit increase in 'Monitoring and Business Assistance Intensity' results in the log odds of the dependent variable 'Our company is making profit' increasing by $29.5 \%$ (1.295$1=.295$ ). The 'Professional Management Services' impact is slightly smaller in this category, where a one-unit increase in Professional Management Services results in the increase of the dependent variable by $13 \%(1.13-1=.13)$. The hypothesised propositions between Selection Performance, Monitoring and Business Assistance Intensity and Professional Management Services with Business Incubation Performance are hence supported. Incubators that develop targeted strategies and practices concerning Selection Performance, Monitoring and Business Assistance Intensity, and Professional Management practices are more likely to produce incubatees that are making profit.

Table 3: Parameter estimates for the full model

\begin{tabular}{|c|c|c|c|c|c|}
\hline $\begin{array}{l}\text { Group 1: Our company has met its break-even and } \\
\text { is moving on a path to profitability }\end{array}$ & $\boldsymbol{\beta}$ & SE $\beta$ & Wald's $\chi^{2}$ & $\mathbf{p}$ & $\begin{array}{c}\mathrm{e}^{\beta} \\
\text { (odds } \\
\text { ratio) }\end{array}$ \\
\hline \multicolumn{6}{|l|}{ Predictor } \\
\hline Constant & .176 & 2.943 & .004 & .952 & \\
\hline Selection Performance (F1) & .001 & .024 & .002 & .963 & .999 \\
\hline Monitoring and Business Assistance Intensity (F2) & .000 & .061 & .000 & .998 & 1.000 \\
\hline Resource Allocation (F3) & .057 & .043 & 1.762 & .184 & .944 \\
\hline Professional Management Services (F4) & .020 & .026 & .585 & .444 & 1.020 \\
\hline \multicolumn{6}{|l|}{ Group 2: Our company is making profit } \\
\hline Constant & 35.271 & 14.425 & 5.979 & .014 & \\
\hline Selection Performance (F1) & .195 & .075 & 6.731 & .009 & 1.215 \\
\hline Monitoring and Business Assistance Intensity (F2) & .258 & .107 & 5.828 & .016 & 1.295 \\
\hline Resource Allocation (F3) & .026 & .084 & .098 & .754 & 1.027 \\
\hline Professional Management Services (F4) & .122 & .047 & 6.618 & .010 & 1.130 \\
\hline \multicolumn{6}{|l|}{ Group 3: Our company is highly profitable } \\
\hline Constant & 41.092 & 22.568 & 3.315 & .069 & 41.092 \\
\hline Selection Performance (F1) & .265 & .134 & 3.914 & .048 & 1.304 \\
\hline Monitoring and Business Assistance Intensity (F2) & .145 & .182 & .640 & .424 & 1.156 \\
\hline Resource Allocation (F3) & .083 & .138 & .356 & .551 & 1.086 \\
\hline Professional Management Services (F4) & .202 & .099 & 4.162 & .041 & 1.223 \\
\hline
\end{tabular}

a. The reference category is 'Our company is barely surviving'

With reference to Category 3 (Our company is highly profitable), two variables were statistically significant in predicting business incubation performance: 'Selection Performance' and 'Professional Management Services'. The value of the log odds $\left(e^{\beta}\right)$ is 1.304 implying that for 
each unit increase in Selection Performance, the odds of superior profitability increase by 30.4\% (1.304-1=.304). Professional Management Services also has a significant impact in Category 3 whereby an increase in each unit increases the odds of higher profitability by $22.3 \%(1.223-1=.223)$. These relationships suggest that incubators with clearly developed Selection Performance metrics and who provide targeted Professional Management Services are more likely to produce highly profitable incubatees.

\section{Statistical tests of individual predictors}

The statistical significance of individual regression coefficients $(\beta \mathrm{s})$ was tested using the Wald chi-square statistic. As highlighted in Table 3, constructs F1, F2, and F4 were significant predictors of the second group with outcome category "Our companies are making profit" ( $p<$ $.05)$ with high corresponding Wald test values (F1: $\left.\chi^{2}=6.731 ; F 2: \chi^{2}=5.828 ; F 4: \chi^{2}=6.618\right)$. This indicates that incubatees are more likely to be profitable if they are carefully selected, provided adequate monitoring and business assistance, and are nurtured and developed via targeted Professional Management Services. Interestingly however, merely providing incubatees with resources does not necessarily aid them towards reaching profitability. If we examine Category 3, F1 and F4 were significant predictors for the outcome category 'Our company is highly profitable' with $\chi^{2}=(3.914$ and 4.162$)$ respectively. This indicates that companies tend to be more highly profitable when incubators select the incubatees carefully, and provide them with targeted Professional Management Services. The results also tend to indicate that as with Category 2 the mere provision of resources will not result in desired outcomes. Additionally, companies who are operating at a higher level do not require as much monitoring and operational level assistance.

\section{Goodness-of-fit statistics}

Goodness-of-fit statistics were used to assess the fit of the logistic model against actual outcomes. Two descriptive measures are presented in Table 4; the $R^{2}$ indices defined by Cox and Snell (1989) and Nagelkerke (1991), respectively. These indices are variations of the $R^{2}$ concept defined for the OLS regression model (Ordinary Least Squares). Whilst in linear regression, $R^{2}$ defines the amount of variation in the dependent variable explained by the model predictors, in logistic modelling the indices can be treated as supplementary to each other, though care must be taken in any inferential framework (Menard, 2000). The Cox and Snell $R^{2}$ measure indicates a greater model fit with higher values, but with a limit of $<1$ (Hair et al., 2010), while the Nagelkerke $R^{2}$ is an adjusted version of the Cox and Snell $R^{2}$ and covers the full range from 0-1, and therefore it is often preferred (Hair et al., 2010). These $R^{2}$ values essentially indicate how useful the explanatory variables are in predicting the response variable and can be referred to as measures of effect size.

Table 4: Goodness-of-fit tests of the full model

\begin{tabular}{|l|c|c|c|}
\hline & Chi-Square & df & p \\
\hline Pearson & 257.923 & 297 & .951 \\
\hline Deviance & 217.464 & 297 & 1.000 \\
\hline $\mathrm{R}^{2}$ & & & .297 \\
\hline Cox and Snell & & & .326 \\
\hline Nagelkerke & & & \\
\hline
\end{tabular}

The value of Cox \& Snell $R^{2}$ is .297 and reveals that about $30 \%$ of the variation in the outcomes is explained by the model bearing in mind this measure cannot achieve a maximum value of 1 . Similarly, the Nagelkerke $R^{2}$ was computed as .326, indicating that about $33 \%$ of the variation in the outcome variable is explained by the logistic regression model. Table 4 shows the Pearson residual and the Deviance residual used to measure the difference between the 
observed and the fitted values: both indicate the model fits to the data well. In other words, the null hypothesis of a good model fit to data is tenable.

\section{Validations of predicted probabilities.}

Logistic regression predicts the logit of an event outcome from a set of predictors. The resultant predicted probabilities are then revalidated with the actual outcome to determine if high probabilities are indeed associated with events and low probabilities with non-events. The degree to which predicted probabilities agree with actual outcomes is expressed as either a measure of association or a classification table. Peng, Lee and Ingersoll (2002) recommend the use of classification in addition to the overall evaluation table to help communicate findings to readers.

Table 5: Classification table for the full model

\begin{tabular}{|c|c|c|c|c|c|}
\hline \multirow[b]{2}{*}{ Observed } & \multicolumn{5}{|c|}{ Predicted } \\
\hline & \begin{tabular}{|} 
Our company is \\
barely surviving
\end{tabular} & \begin{tabular}{|} 
Our company \\
has met its \\
break-even \\
and is \\
moving on a \\
path toward \\
profitability
\end{tabular} & $\begin{array}{c}\text { Our company is } \\
\text { making profit }\end{array}$ & $\begin{array}{c}\text { Our company is } \\
\text { highly } \\
\text { profitable }\end{array}$ & $\%$ Correct \\
\hline $\begin{array}{l}\text { Our company is } \\
\text { barely surviving }\end{array}$ & 12 & 6 & 10 & 0 & $42.9 \%$ \\
\hline $\begin{array}{l}\text { Our company has } \\
\text { met its break-even } \\
\text { and is moving on a } \\
\text { path to profitability }\end{array}$ & 8 & 14 & 14 & 1 & $37.8 \%$ \\
\hline $\begin{array}{l}\text { Our company is } \\
\text { making profit }\end{array}$ & 3 & 8 & 24 & 1 & $66.7 \%$ \\
\hline $\begin{array}{l}\text { Our company is } \\
\text { highly profitable } \\
\end{array}$ & 1 & 0 & 2 & 1 & $25.0 \%$ \\
\hline Overall Percentage & $22.9 \%$ & $26.7 \%$ & $47.6 \%$ & $2.9 \%$ & $48.6 \%$ \\
\hline
\end{tabular}

The classification table (Table 5) presents a contingency table of observed versus predicted responses for all combinations of predictor variables indicating the extent to which the model correctly predicts each outcome category. The benchmark used to characterise a multinomial logistic regression model as useful is a $25 \%$ improvement over the rate of accuracy achievable by chance alone (Abdullah, 2009). Table 5 details that the full model classifies $48.6 \%$ correctly, well above the $39.5 \%(1.25 \times 31.6 \%=39.5 \%)$ chance accuracy criteria hence, classification accuracy is satisfied by these results.

In summary, this study examining ICT incubation performance modelled four outcome categories: 'Our company is barely surviving'; 'Our company has met its break-even and moving on a path toward profitability'; 'Our company is making profit'; and 'Our company is highly profitable'. The population survey of ICT incubators in Malaysia revealed that 32 firms (27.1\%) were barely surviving, 44 firms (37.3\%) had met their break-even, 38 firms (32.2\%) were making profit, and 4 firms (3.4\%) were highly profitable.

\section{DISCUSSION AND RECOMMENDATIONS}

The research results highlight that a 'one-size-fits-all' approach is inappropriate. Moreover, as Aerts, Matthyssens, and Vandenbempt (2007) and Bruneel, Ratinho, Clarysse and Groen (2012) have shown us in their examination of the European business incubator landscape, a critical starting point in maximising performance outcomes - is for incubator management to subject potential clients 'to a severe screening process'. Meeting tenancy quota benchmarks 
more often than not, masks the true viability potential of incubatees and serves a distracting purpose of being a 'complicit testamur' in gaining further government funding. Transparent expectations on both sides of the ledger are necessary in achieving the age-old adage of 'quality in - quality out'. A number of studies have been conducted into effective selection practices and in broad terms selection metrics can be grouped into three categories around management, finances and market. Building on the work of Lumpkin and Ireland (1988) Aerts et al. (2007) developed a 'screening index' incorporating measures related to these three categories. Such an index provides incubation managers with a useful tool in assessing potential incubatees, however our results also point to the interconnectedness between the three categories and that trajectory interventions will differ depending on the incubation lifecycle of incubatees.

Whilst the four propositions developed for this research were all confirmed, it is telling that highly performed incubator firms were very much in the minority. Interestingly, resources provided became less significant as incubatees became more profitable whilst targeted professional management services increased in significance suggesting that as profitability improves the need for capability development increases. Returning to the notion of interconnectedness, not just of elements of selection criteria but also of monitoring and assistance intensity, resource provision and allocation and targeted professional management services; timing is a critical factor in facilitating better incubation performance. The incubation process cannot be solely reliant on provision, indeed that could lead to undesirable outcomes such as overly reliant and reactive incubatees. What is required is suitable guidance offered at different stages of the incubation cycle and this support should be more heavily weighted toward capability enhancement as opposed to resource provision. A culture of dependency must be avoided instead incubatees require guidance and support in the execution of taking embryonic concepts to market. To accelerate this process lean methodologies supported by design thinking and design practices ${ }^{1}$ may be useful in stress-testing product/service development in terms of desirability, feasibility and viability. This requires a more tactical approach by the incubator managers. Whilst the need for planning, organising, leading, and controlling should not be understated, incubator managers need to also be equipped with more agile entrepreneurial approaches. In order for this to be possible, incubator managers need to be attentive to incubatees' needs and be prepared to enhance the development of a conducive entrepreneurial ecosystem supporting the incubators.

Co-designing approaches driven by design thinking and design tools whereby products and services are rapidly prototyped in collaboration with end-users can achieve four critical outcomes. Firstly, minimum viable resources are used as required, reducing waste and overcoming duplication issues. Secondly, it shifts the development paradigm from a push model where products and services are developed 'in-house' then pushed to market using various marketing channels. Instead a pull model is enabled whereby end-users are part of the iterative development cycle from the beginning. Thirdly, enhanced connectivity between incubatees, the incubator and the surrounding ecosystem will serve to foster greater levels of collaboration and entrepreneurship. Incubator managers would be well served by diversifying such ecosystems via an 'inside-out outside-in' approach that sees the venture socialised with end-users during the development phase and brings high level external capability (including alumni) into the incubator at critical moments in translating ideas into desirable, feasible and viable products and services. Lastly, the graduation of viable firms out of the incubator is

${ }^{1}$ For an overview see e.g. Beckman \& Barry, (2007); Brown, (2008); or Korst, (2011). 
accelerated and in so doing contributes to a greater critical mass of firms driving innovation at both a local and national level and potentially also at a global level.

\section{ACKNOWLEDGEMENT}

I would like to take the opportunity to thank Universiti Teknikal Malaysia Melaka (UTeM) for making this research and publication possible. This article is published as part of the Research Acculturation Grant Scheme (RAGS) with the grant number RAGS/2012/UTEM/SS05/B00021 led by the first author. I would also like to thank the co-authors Assoc. Prof. Dr. David Gilbert and Dr. Afreen Huq of RMIT University for their dedication during this research.

\section{References}

Abdullah, R. N. (2009). Self Esteem, Gender and Academic Achievement of Undergraduate Students. American Journal of Scientific Research, 3(3), 26-37.

Abdul Khalid, F., Gilbert, D., Huq, A. (2012). Third-generation busniess incubation practices in Malaysian ICT Incubators - A bridge too far? American Journal of Management 12 (2/3), 88-107

Aerts, K., Matthyssens, P., \& Vandenbempt, K. (2007). Critical role and screening practices of European business incubators. Technovation, 27(5), 254-267. http://doi.org/10.1016/j.technovation.2006.12.002

Albert, P., \& Bernasconi, M. (2002). Incubators : the Emergence of a New Industry a Comparison of the Players and Their Strategies : Finance.

Bergek, A., \& Norrman, C. (2008). Incubator best practice: A framework. Technovation, 28(1-2), 20-28. http://doi.org/10.1016/j.technovation.2007.07.008

Bruneel, J., Ratinho, T., Clarysse, B., Groen, a, \& Cock, R. D. E. (2010). Incubation Centers : Comparing Their Support. Agse 2010, 861-875. Retrieved from http://www.swinburne.edu.au

Bruneel, J., Ratinho, T., Clarysse, B., \& Groen, A. (2012). The evolution of Business incubators: Comparing demand and supply of business incubation services across different incubator generations. Technovation, 32(2), 110-121. http://doi.org/10.1016/j.technovation.2011.11.003

Bulsara, H. P., Porey, P. D., \& Gandhi, S. (2010). Commercialization of technology innovations and patents - Issues and challenges. In K. Ramanathan, S. Nanjundappa, S. Satyabrata, G. Clar, \& M. Henzler (Eds.), Asia-Pacific Tech Monitor (p. 66). Asian and Pacific Centre for Transfer of Technology. Retrieved from http://www.techmonitor.net/tm/images/b/ba/10nov_dec.pdf\#page=14

Chan, K. F., \& Lau, T. (2005). Assessing technology incubator programs in the science park: The good, the bad and the ugly. Technovation, 25(10), 1215-1228. http://doi.org/10.1016/j.technovation.2004.03.010

Che Senik, Z. (2010). Models, processes, and factors influencing internationalization: The case of Malaysian SMEs.

Costa-David, J., Malan, J., \& Lalkaka, R. (2002). Improving Business Incubator Performance through Benchmarking and Evaluation -_- Lessons learned from Europe.pdf. Nbia, 27.

Grimaldi, R., \& Grandi, A. (2005). Business incubators and new venture creation: An assessment of incubating models. Technovation, 25(2), 111-121. http://doi.org/10.1016/S0166-4972(03)00076-2

Hackett, S. M. (2004). Real options and the option to incubate: An exploratory study of the process of business incubation.

Hackett, S. M., \& Dilts, D. M. (2008). Inside the black box of business incubation: Study B - Scale assessment, model refinement, and incubation outcomes. Journal of Technology Transfer, 33(5), 439-471.

http://doi.org/10.1007/s10961-007-9056-9

Hamdani, D. (2006). Conceptualizing and measuring Business Incubation. Statistics Canada, 1(S3), 1-25. http://doi.org/10.1002/1097-0142(19910201)67:3+<774::AID-CNCR2820671404>3.0.CO;2-I

Infodev. (2008). Promoting ICT-enabled Innovation and Entrepreneurship in Developing Countries through Business incubation.

Lumpkin, J. R., \& Ireland, R. D. (1988). Screening Practices of New Business Incubators : The Evaluation of Critical Success Factors. American Journal of Small Business, Spring, 59-82.

McAdam, M., \& McAdam, R. (2008). High tech start-ups in University Science Park incubators: The relationship between the start-up's lifecycle progression and use of the incubator's resources. Technovation, 28(5), 277-290. http://doi.org/10.1016/j.technovation.2007.07.012 
Mian, S. A. (1994). US university-sponsored technology incubators : an overview of management, policies and performance, 14(8), 515-528.

National Business Incubation Association, 2012 White Paper Series. Accessed January 18, 2016.

(http://www2.nbia.org/resource_library/review_archive/archive_operations.php).

Peters, L., Rice, M., \& Sundararajan, M. (2004). The Role of Incubators in the Entrepreneurial Process. The Journal of Technology Transfer, 29, 83-91. http://doi.org/10.1023/B:JOTT.0000011182.82350.df

Ramasamy, B., Chakrabarty, A. \& Cheah, M. (2003). Malaysia's leap into the future: an evaluation of the multimedia super corridor. Technovation, 24(11), 871-883.

Sun, H., \& Leung, J. (2007). Critical Success Factors for Technological Incubation : Case Study of Hong Kong Science and Technology Parks, 24(2), 346-364

Warren, L., Patton, D., \& Bream, D. (2009). Knowledge acquisition processes during the incubation of new high technology firms. International Entrepreneurship and Management Journal, 5(4), 481-495.

http://doi.org/10.1007/s11365-009-0121-8

Knopp, L. 2012 'State of the business incubation industry'. NBIA Publications pp.1-66 ISBN: 978-1-887183-72-7 